Miguel Naranjo, P. (2019): “Calatrava la Vieja (Carrión de Calatrava, Ciudad Real) durante la Primera Edad del Hierro (c. fin. s. VIII-550 a.C.)", Spal 28.1: 79-96. DOI: http://dx.doi.org/10.12795/spal.2019.i28.04

\title{
CALATRAVA LA VIEJA (CARRIÓN DE CALATRAVA, CIUDAD REAL) DURANTE LA PRIMERA EDAD DEL HIERRO (C. FIN. S. VIII-550 A.C.)
}

\author{
CALATRAVA LA VIEJA (CARRIÓN DE CALATRAVA, CIUDAD REAL) \\ DURING THE EARLY IRON AGE (LATE 8TH CENTURY-550 BC)
}

\author{
PEDRO MIGUEL NARANJO \\ Área de Prehistoria (Departamento de Historia). Facultad de Letras. Universidad de Castilla-La Mancha. \\ Avda. Camilo José Cela, s/n, 13071, Ciudad Real. Correo-e: Pedro.Mnaranjo@uclm.es. (D) https://orcid.org/0000-0003-4356-4511
}

\begin{abstract}
Resumen: En este trabajo se estudian todos aquellos materiales cerámicos de Calatrava la Vieja hallados fuera de contexto, insertos en la Primera Edad del Hierro según los estudios tipológicos, y los únicos de época protohistórica hallados in situ hasta la fecha (A-16). El estudio de los materiales y la estratigrafía ha permitido la inserción de Calatrava la Vieja en las redes comerciales y culturales de la época, así como la continuidad del poblamiento de finales de la Primera Edad del Hierro con el inicio de la fase ibérica. Con ello se pretende arrojar luz sobre una de las etapas peor conocidas de la parte más meridional de la Meseta Sur y que supuso una fase fundamental en la gestación de los posteriores oppida ibéricos. Palabras clave: Calatrava la Vieja, Hierro I, Meseta suroriental, tipología, cerámica.
\end{abstract}

\section{INTRODUCCIÓN}

Calatrava la Vieja (Carrión de Calatrava, Ciudad Real) se sitúa en la orilla izquierda del río Guadiana sobre una altura de entre los 5 y $10 \mathrm{~m}$ con respecto al espacio circundante, ubicación que le permitió el control visual de un entorno dominado por fértiles llanos (fig. 1). Aunque el yacimiento es conocido por la fundación de la ciudad
Abstract: In this paper, we study all ceramics without context which inserted in the First Iron Age according to the typological studies and the only materials found in situ in Calatrava la Vieja (A-16) during the Protohistory. The study of the materials and the stratigraphy has allowed to conclude the insertion of Calatrava la Vieja in the commercial and cultural networks of that time, as well as the continuity of this place during the beginning of the Iberian phase. This allow to know one of the most unknown stages in the Southern Plateau, which was a fundamental phase in the training of the later Iberian oppida.

Key Words: Calatrava la Vieja, Early Iron Age, Southeast Iberian Plateau, typology, pottery.

islámica de Qalat Rabalh (Retuerce 1994: 212-241), diversos materiales fuera de contexto han revelado unas fases de ocupación previa cuyos niveles yacen bajo los potentes estratos medievales. Dichos materiales, recuperados entre los basureros y tapiales de época medieval, permitieron marcar el inicio del poblado en el Bronce Final (Blanco et al. 2012: 85-150). Probablemente el enclave no alcanzó una complejidad destacada hasta época íbera, como así refleja la variedad cerámica 
o los restos de muralla conservados que debió circundar un espacio de aproximadamente 6 ha (Retuerce y Hervás 2004: 391).

Los trabajos de campo llevados a cabo durante 1998 en el interior de la fortaleza medieval, concretamente en una de las habitaciones de la Encomienda de Calatrava (Área 16), sacaron a la luz algunos materiales protohistóricos que motivaron una intervención adicional en 1999. En el desarrollo de dichos trabajos se diferenciaron dos fases, una de época ibérica y otra que se situó en el periodo transicional Bronce Final-Hierro I. En el nivel ibérico se documentaron dos posibles hornos de pan separados entre sí por unos $3 \mathrm{~m}$ de distancia (García Huerta et al. 2006: 159-160). Se constataron cinco unidades estratigráficas, denominadas UU. EE. 77, 78, 79, 80 y 81 , advirtiendo en todo momento algunas alteraciones por la construcción de los muros medievales. Sin embargo, en la revisión de los materiales no se ha registrado ninguna intrusión de época medieval que indique una alteración profunda. De todos estos materiales exhumados, solo se señaló la aparición de fragmentos de cerámica a mano e ibérica, una fusayola y restos de fauna (García Huerta et al. 2006: 160). Este conjunto material fue fechado entre finales del siglo VII o principios del VI a.C. (Morales 2010: 102), aunque no se precisaron las formas adscritas a cada una de las fases diferenciadas.

El presente trabajo tiene como objetivo principal estudiar todo el material correspondiente a la Primera Edad del Hierro en Calatrava la Vieja, tanto las piezas recopiladas por Blanco et al. (2012) como las del Área 16 (A-16). A este conjunto se suman los nuevos ejemplares documentados entre 2010 y 2017. Con ello se busca ampliar la tipología de una de las etapas peor conocidas en la Meseta Sur, ya que los dos trabajos apuntados no profundizaron en la definición de las formas o las decoraciones que definen la Primera Edad del Hierro. Dicha fase enlazaría con los periodos que fosilizan los niveles del Área A-16, hasta el momento los únicos in situ de Calatrava la Vieja antes de época medieval. La información recabada a partir del estudio de estos materiales, fundamentalmente cerámicos, permitirá una aproximación de los contactos que las poblaciones de Calatrava mantuvieron con otras áreas coetáneas de la península ibérica. Por otro lado, la publicación de las únicas formas anteriores a época medieval halladas en su contexto original permitirá situar todas aquellas cerámicas descontextualizadas que hallan su paralelo en dichos modelos.

Del material exhumado fuera de contexto que corresponde a la Primera Edad del Hierro, han sido seleccionadas exclusivamente las cerámicas a mano por motivos de espacio y con el fin de ofrecer un estudio detallado de las mismas. Sin embargo, la cerámica a mano de este periodo convivió con las primeras cerámicas a torno como ocurre en La Bienvenida (Fernández Ochoa et al. 1994: 145) o El Cerro de las Cabezas (Vélez y Pérez 1987: 173-174; 1999: 51-53). Para el caso de los materiales del A-16, sí que se han incluido las producciones a mano y a torno por tratarse de contextos sin alterar.

Las formas reconocidas fuera de contexto se han podido ubicar en este periodo atendiendo a los paralelos estratificados en otros yacimientos, así como en las unidades identificadas en el A-16 donde sí que se puede establecer una asociación de materiales. Muchas de estas analogías se han hallado en yacimientos lejanos a Calatrava, aunque se le ha dado mayor relevancia a la posición que las distintas formas presentan en los yacimientos aledaños con el fin de ajustarse a la realidad circundante (fig. 1). Algunas de las formas reconocidas en Calatrava se encuentran recogidas en la tipología de Ruíz Mata (1995: 265-313), como las copas B.II o las ollas G.I, una sistematización que se estableció para la cerámica a mano del Suroeste según criterios formales y cronológicos que recientemente se han reafirmado (Ruíz Mata 2014: 1-11).

Todo el material estudiado ha sido sometido a un análisis macroscópico en el que se ha observado una clara diferencia entre las producciones según su funcionalidad, criterio que se ha utilizado para su clasificación. Así, las formas relacionadas con la cocina de alimentos se caracterizan por las pastas poco depuradas, cocciones irregulares y superficies ligeramente alisadas. En contraste, los vasos destinados al servicio o consumo de alimentos destacan por unas pastas de granulometría media o fina, cocciones regulares y superficies alisadas o bruñidas. Por último, estarían aquellas producciones destinadas a momentos puntuales que se caracterizan por un tratamiento especial que limitarían su utilización.

Pese a todo, serán las futuras excavaciones las que permitan verificar o rechazar lo que se ha apuntado. Dichos trabajos ofrecerán dataciones o asociación de materiales más fiables, de ahí la importancia de la continuidad de los trabajos en este yacimiento.

\section{ESTUDIO DEL MATERIAL: LAS FORMAS}

\subsection{Cerámica de cocina}

\subsubsection{Ollas a mano de perfil globular y cuello estrangulado}

El recipiente por excelencia para la cocina de alimentos es la olla, de perfil globular y cuello más o menos 


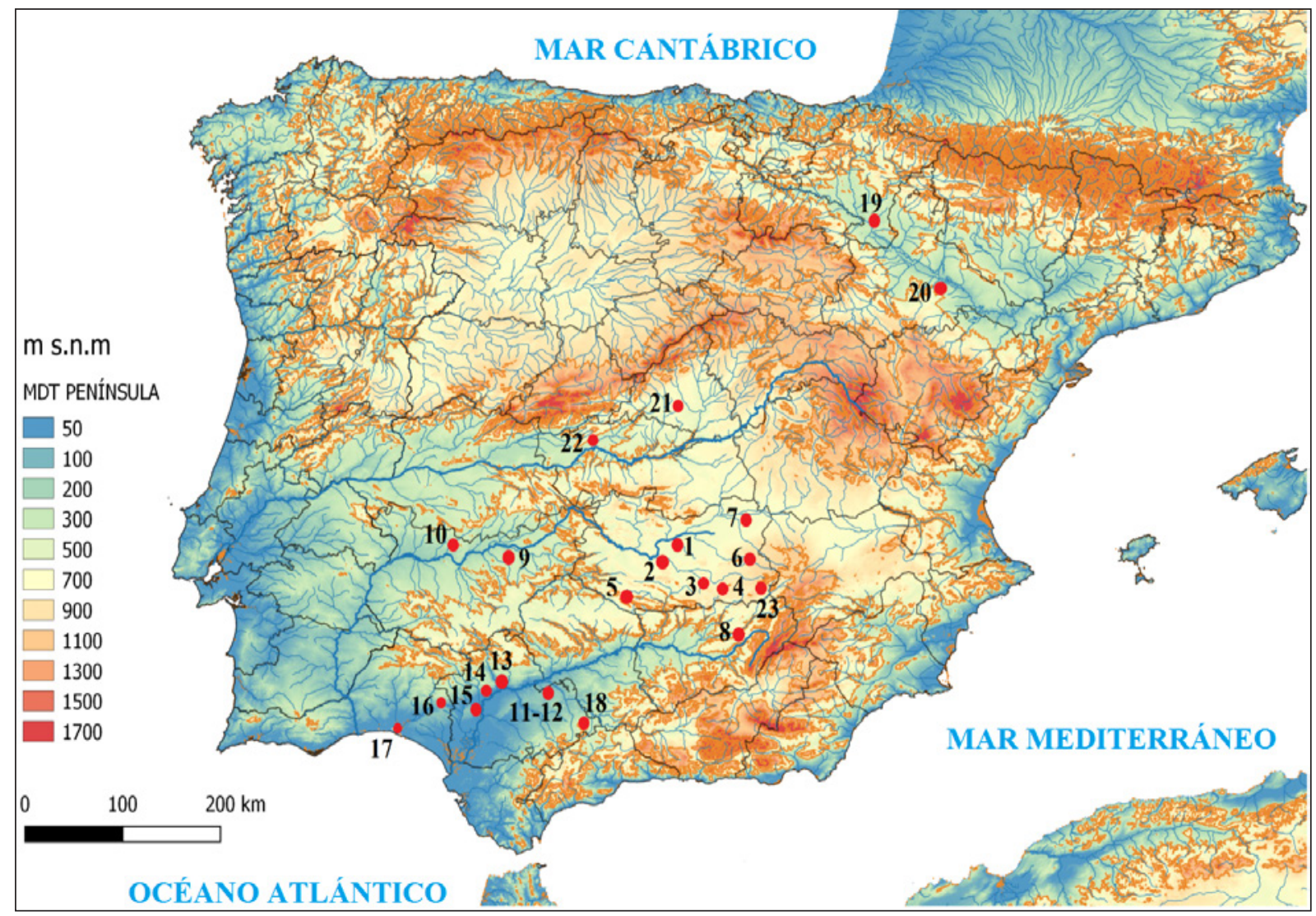

Figura 1. Yacimientos citados en el texto: 1. Calatrava la Vieja (Carrión de Calatrava, Ciudad Real); 2. Alarcos (Poblete, Ciudad Real); 3. Casa de Rana (Valdepeñas, Ciudad Real); 4. Cerro de las Cabezas (Valdepeñas, Ciudad Real); 5. La Bienvenida-Sisapo (Almodóvar del Campo, Ciudad Real); 6. Peñarroya (Argamasilla de Alba, Ciudad Real); 7. Cerro de las Nieves (Pedromuñoz, Ciudad Real); 8. Cástulo (Linares, Jaén); 9. Medellín (Badajoz); 10. Los Concejiles (Lobón, Badajoz); 11. Vega de Santa Lucía (Palma del Río, Córdoba); 12. La Saetilla (Palma del Río, Córdoba); 13. Cerro Macareno (La Rinconada, Sevilla); 14. El Carambolo (Camas, Sevilla); 15. Valencina de la Concepción (Sevilla); 16. Peñalosa (Escacena del Campo, Huelva); 17. Cabezo de San Pedro (Huelva); 18. Osuna (Sevilla); 19. Cortes de Navarra (Navarra); 20. Cabezo de la Cruz (La Muela, Zaragoza); 21. Arroyo Culebro (Leganés, Madrid); 22. El Carpio (Belvís de la Jara, Toledo). 23 Mentesa Oretana (Villanueva de la Fuente, Ciudad Real). Elaboración propia a partir del programa de SIG Qgis.

estrangulado. Dicha función queda reflejada en el evidente descuido en la factura o la presencia de las manchas negras en el tercio inferior de algunas de ellas, como consecuencia de una prolongada y asidua exposición al fuego. Algunas de las ollas sin contexto se relacionan con la forma G.I.c.1 de la tipología de Ruíz Mata (1995: 270, fig. 3: 18-22), un recipiente de cuerpo ovoide, fondo plano, borde generalmente corto y labio redondeado. Dentro de este tipo se pueden distinguir entre ollas de mayor tamaño (fig. 2.1: CV/02/28/52/2, fig. 2.2: CV/00/17/1/1455), de pastas groseras y superficies descuidadas, y otras más pequeñas en las que las pastas están más depuradas y las superficies alisadas o ligeramente bruñidas (CV/19/206/1, CV/30/96/6). Morfológicamente, podrían realizarse algunas precisiones en función de la arista interna o la configuración del labio. Así, se distinguiría un subgrupo (CV/30/96/6, fig. 2.2) caracterizado por un estrangulamiento más agudo del cuello y el labio apuntado, reservándose una zona plana interna para el reposo de algún tipo de tapadera. El segundo subgrupo diferenciado, con un cuello menos marcado, quedaría definido por un borde más redondeado y exento de la parte plana entre el labio y el cuello (CV/19/206/ lám. 1, fig. 2.1). Este segundo subgrupo muestra paralelos con los materiales de Arroyo Culebro que fueron fechados en la Primera Edad del Hierro (Blasco et al. 1998: 253, lám. 5: 4), aunque dicha forma debió perdurar durante el Ibérico Antiguo como constatan los ejemplares de las UU. EE. 77 y 78 del 
A-16 (fig. 2.3: CV/16/77/16, CV/16/78/12+13). Esta olla convivió con otra de perfil más elipsoide (CV/16/77/15), todas ellas de fondo plano como así revelan las bases de estos niveles (CV/16/77/14).

La olla G.I fue vinculada al ámbito tartésico entre los siglos IX-VII a.C. (Ruíz Mata 1995: 267, 270-271), si bien es cierto que se trata de un recipiente común a varios periodos cronoculturales. Dicha cronología parece corroborada por un ejemplar de El Carambolo IV (Casado 2015: 121-124, fig. 2: DJ2002/24/2481 - 13), fase fechada entre mediados del siglo VIII y principios del VII a.C. (Fernández Flores y Rodríguez Azogue 2007: 123-125). Cástulo también ha proporcionado algunos ejemplares afines en prácticamente toda su secuencia estratigráfica, que abarca desde principios del siglo VIII a finales del VII a.C. (Blázquez y Valiente 1981: figs. 14:288, 117:677, 119:1057, 142:1221, 147:1252). De la primera Edad del Hierro también son los ejemplares de Osuna (Ferrer et al. 2017: fig. 1: 3) o Medellín (Almagro-Gorbea 1977: 481, fig. 176:6841).

Este tipo de forma se documenta en los niveles orientalizantes y del Ibérico Antiguo de La Bienvenida (Fernández Ochoa et al. 1994: figs. 117:49; 108:61, 62; 96:76, 77; 89:38; 72:42; 73:43; 66:21, 20; Zarzalejos et al. 2017: fig. 12:2), apreciándose en todo momento las similitudes con los análogos ejemplares andaluces del siglo VII a.C. Semejantes recipientes se constatan también en el Cerro de las Cabezas, con superficies toscas y cuellos más o menos marcados (Vélez y Pérez Avilés 1987: lám. II: 17; Esteban et al. 2003: 17), situándose cronológicamente en momentos avanzados del siglo VII a.C. y en una conexión cultural con el ámbito tartésico orientalizante (Esteban et al. 2003: 26). No obstante, y pese a estas concomitancias con los recipientes de otras áreas de la península ibérica, habría que considerar las similitudes con algunas formas que componen la tradición alfarera del Bronce Medio (García Pérez 1987: fig. 14) y que probablemente se perpetuaron hasta estas fechas. De hecho, para el caso de Peñarroya se apuntó dicha perduración al estudiar unas formas análogas que oscilan en torno al siglo VI a.C. (García Huerta et al. 1999: 233, 249, fig. 6:1, 2) o poco antes (Benítez de Lugo et al. 2004: 67).

\subsection{Cerámica para el servicio o presentación de alimentos}

\subsubsection{Grandes cuencos a mano de perfil semiesférico}

Este cuenco de perfil semiesférico, con $40 \mathrm{~cm}$ de diámetro y $11 \mathrm{~mm}$ de grosor máximo conservado, revela una forma abierta y poco profunda (fig. 3.1: CV/16/80/6+10; CV/16/80/12). Aunque su pasta no está muy depurada, las superficies recibieron un bruñido que fue mucho más intenso en la parte interna y el borde. Este cuidado en el tratamiento, unido a sus grandes dimensiones y la ausencia de manchas por exposición al fuego, confirmaría su uso como forma para el servicio de alimentos, ya que para el almacenamiento fueron más comunes las formas cerradas y de mayor grosor.

El cuenco semiesférico se trata de una forma simple y ampliamente representada en varias culturas peninsulares. En Calatrava aparece estratificado en la U.E. 80, unidad inserta en una fase de finales de la Edad del Hierro o de transición hacia el Ibérico Antiguo. Aunque este dato permite situar dicha forma en estos contextos, es muy probable que estuviera presente en fases anteriores.

\subsubsection{Cuencos a mano de perfil troncocónico}

Esta forma se ha documentado tanto fuera de contexto (fig. 3.1 CV/26/637/3) como en los niveles del Ibérico Antiguo del A-16 de Calatrava la Vieja (3.2: CV/16/77/15, CV/16/77/17, CV/16/77/20). Algunos de ellos presentan amplios grosores y diámetros de hasta $25 \mathrm{~cm}$, lo que hace pensar en una forma destinada a presentar los alimentos en la mesa. El cuenco troncocónico se documenta entre el repertorio cerámico de la Meseta Norte durante el Bronce Final y la Primera Edad del Hierro, vinculándose tradicionalmente a las influencias de Campos de Urnas (Pellicer 1984: 323, fig. 9: A, C, D, E; Werner 1990: figs. 17, 18, 31; Ruíz Zapatero 2007: fig. 7). De hecho, fue en la Meseta Norte y en esta corriente cultural donde se buscaron los paralelos para las producciones extremeñas de época post-orientalizante (Rodríguez Díaz 1990: 139-140, fig. 4: 6 y 7). Sin embargo, para tales fechas se constata también en el nivel 9 del corte D-4 de La Saetilla (Murillo 1994: 4.73: 1069), Cástulo (Blázquez y Valiente 1981: fig. 56: 475) o Medellín (Jiménez y Guerra 2012: figs. 8:5, 21:8).

Esta forma se fechó en el Cerro de las Nieves entre los siglos VI-IV a.C. (Fernández Martínez et al. 1994: 118). En Alarcos, los cuencos troncocónicos, decorados con impresiones digitadas en el borde o cubiertos con almagra, aparecen estratificados en el nivel 3 del C-23 que define el Hierro I (Fernández Rodríguez, 2012: 51). Similar adscripción cronológica se concedió a los cuencos análogos del Cerro de las Cabezas, aunque en este 


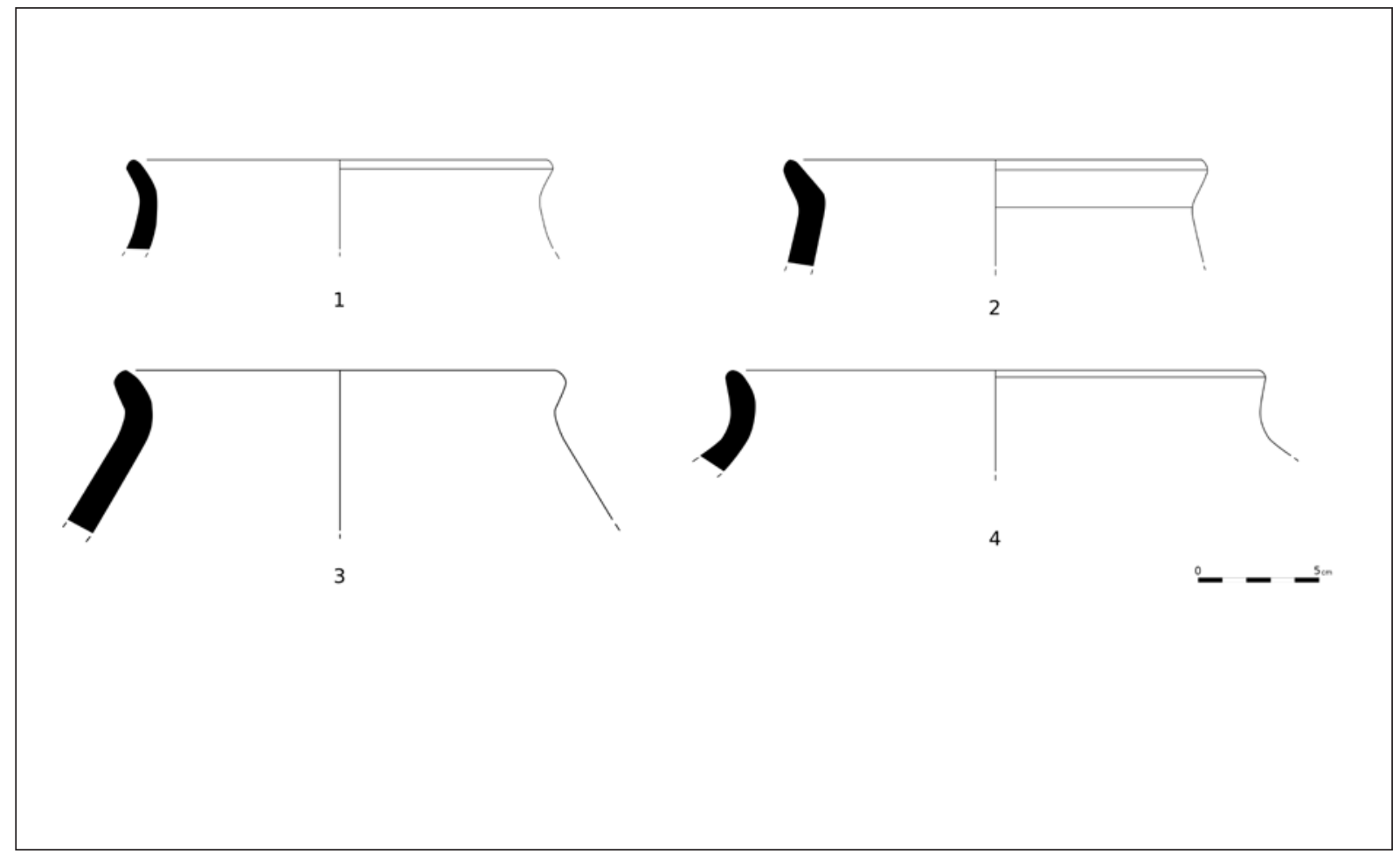

Figura 2. Cerámica de cocina (ollas).

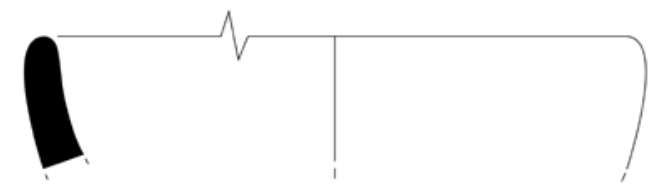

1

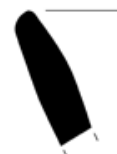

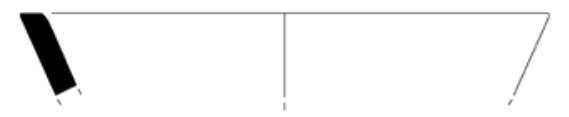

2

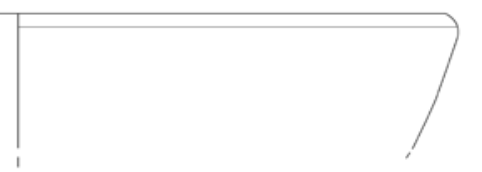

3

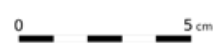

Figura 3 Cerámica para el servicio o presentación de alimentos (cuenco semiesférico: 1 y cuenco troncocónico: 2 y 3). 
caso se han relacionado con el Sureste y no con Campos de Urnas (Esteban et al. 2003: 16, fig. 4: 2).

Los paralelos cercanos al yacimiento de Calatrava la Vieja permiten suponer la presencia del cuenco troncocónico ya en la Primera Edad del Hierro, perpetuándose, al menos, hasta el Ibérico Antiguo. Es probable que ser trate de una forma local, ya que supone un vaso simple que aparece atestiguada en varias culturas, aunque también pudo ser adoptada como consecuencia de los contactos con la Meseta Norte. Sin embargo, los cuencos troncocónicos con decoración digitada o a la almagra de Alarcos, decoración típica del Suroeste y Sureste respectivamente, pondrían de manifiesto la amalgama de unos horizontes decorativos típicos del Mediodía peninsular, fiel reflejo de sociedades híbridas que no reproducen los prototipos sino que los adaptan a sus propios gustos o necesidades.

\subsection{Vajilla fina para el consumo de alimentos}

\subsubsection{Copas a mano del tipo B.II de la sistematización de Ruíz Mata}

Este tipo de cuencos, denominados "copas de paredes finas" por Cabrera (1981: 317-335), constituye un grupo muy definido y uniforme en el que se han distinguido cuatro variedades. En Calatrava la Vieja se constatan tres fragmentos fuera de contexto de este tipo (CV16/12/3, CV15/243/123), uno de ellos un ejemplar (fig. 4.1: CV/98/12/24/6) que corresponde a la forma B.II.a.1 de la tipología de Ruíz Mata (1995: fig. 20:1), caracterizada por un borde corto y cóncavo, separada del cuerpo mediante una carena aristada que en el exterior se dispone en la mitad del recipiente y que apenas se marca por el interior. Presenta una pasta muy depurada, de cocción reductora y superficies negras esmeradamente bruñidas. Las paredes son muy finas, entre los 3 y $5 \mathrm{~mm}$, revelando un recipiente de uso individual de gran calidad.

Las copas del tipo B.II son típicas de la Baja Andalucía tartésica desde finales del siglo VIII y abarcan todo el siglo VII a.C. (Ruíz Mata 1995: 275-276), aunque el reciente hallazgo de esta filiación en la Fase V de El Carambolo V (Casado 2015: fig. 51: DJ2002/24/2544-120+121+127) obligaría a retrotraer su inicio a la primera mitad del siglo VIII a.C. Entre los yacimientos andaluces en los que se documenta esta forma, destaca el Cabezo de San Pedro (Blázquez et al. 1979: fig. 30: 252-257), compartiendo una gran similitud formal y técnica con la copa B.II.a.1 de la Fase III del yacimiento onubense (Blázquez et al. 1979: fig. 49: 523). Dicha fase se fechó entre el 650-550 a.C. (Blázquez et al. 1979: 177), aunque la posterior revisión de la estratigrafía obligó a elevar la cronología de las tres fases registradas (Fernández Jurado 1988-89: 264 cuadro 4). Algunas de estas copas fueron pintadas postcocción con los típicos esquemas radiales que definen el horizonte San Pedro II (Cabrera 1981: 317-335), aunque nuestro ejemplar no debió recibir pintura al solo constatarse en las formas B.II.b.1 y B.II.b.2 (Torres 2002: 158). Este tipo de copas alcanzó puntos más septentrionales que deben ser relacionados con la actividad comercial que se estaba efectuando a través de la posterior Vía de la Plata, como los ejemplares de El Carpio (Belvís de la Jara, Toledo) (Pereira y de Álvaro 1988: fig. 1).

En el Alto Guadiana se puede verificar la presencia de copas de paredes finas pintadas al estilo San Pedro II en los estratos 13, 12 y 11 de Sisapo, aunque fue en el estrato 13 donde se concentró la mayoría de estos ejemplares que remiten claramente al Suroeste (Zarzalejos et al. 2012: 30). También se han hallado en el edificio orientalizante recientemente exhumado, datándose entre finales del siglo VIII-principios del VII a.C. (Zarzalejos et al. 2017: fig. 13). No obstante, las copas de paredes finas sin pintar presentan mayores proporciones en el estrato 12, adscrito al Periodo Orientalizante (650-600 a.C.), manteniendo su presencia hasta el nivel $9 \mathrm{~b}$ que materializa el periodo Ibérico Antiguo (550-450 a.C.) (Fernández Ochoa et al. 1994: 42, 6163, 146). Entre los ejemplares de Alarcos destacan los fragmentos con decoración San Pedro II de los niveles 1 al 4 del C-23, fechados por $\mathrm{C}^{14}$ entre los siglos VIII y VI a.C. (Fernández Rodríguez 2012: 57, 60-61), unas dataciones que corroboran los nuevos hallazgos (García Huerta y Morales 2017: fig. 7:7, fig. 8: 2, 3, 4, 8). Por lo que respecta al Cerro de las Cabezas, las copas de paredes finas del tipo B.II sin decoración se han ubicado en un momento avanzado del siglo VII a.C. (Esteban et al. 2003: 21).

De este modo, tanto los datos de la Baja Andalucía como los del Alto Guadiana sitúan las copas B.II con decoración pintada al estilo San Pedro II en un lapso temporal que abarca los siglos VIII y VII a.C. Sin embargo, la copa B.II.a.1 de Calatrava la Vieja se situaría en la segunda mitad del siglo VII o principios del siglo VI a.C., en función de la posición que presentan estos ejemplares sin decorar en La Bienvenida o el Cerro de las Cabezas. En cuanto al contexto cultural, la presencia de esta forma en el yacimiento manchego ha de ponerse en relación con los contactos mantenidos con el 


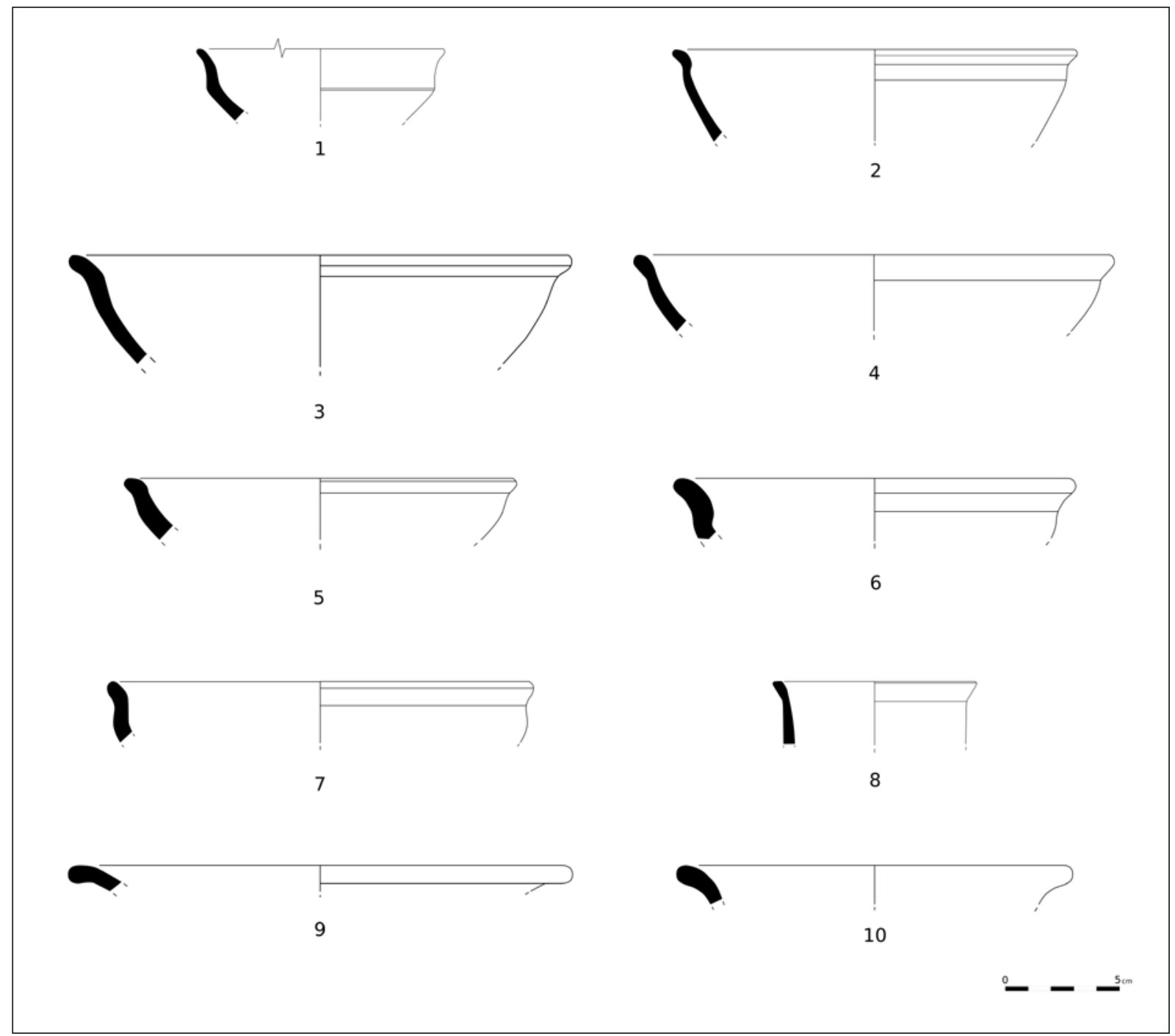

Figura 4. Vajilla fina para el consumo de alimentos (Copa B.II.a.1: 1. Cuencos de perfil semiesférico y borde exvasado del primer subgrupo: 2-7 y del segundo subgrupo: 7. Vaso de paredes finas y cuello cilíndrico: 8. Cerámica ibérica gris: 9 y 10).

ámbito cultural tartésico durante el Periodo Orientalizante, momento en el que dichas relaciones se intensificaron en los poblados circundantes como Alarcos, el Cerro de las Cabezas o La Bienvenida. Dichos contactos se extenderían en un espacio más amplio y alejados del Suroeste, como así constatan los citados materiales de la tumba de El Carpio.

\subsubsection{Cuencos a mano de perfil semiesférico y borde vuelto}

Bajo esta denominación genérica se recogen aquellos recipientes de perfil semiesférico, borde vuelto y paredes más gruesas a las anteriores B.II. Dichos cuencos presentan diámetros que oscilan entre los $17 \mathrm{y} \mathrm{los} 22 \mathrm{~cm}$ y una gran calidad que queda patente en las pastas depuradas de granulometría fina, cocciones regulares y superficies intensamente bruñidas. Los fondos son desconocidos, aunque los paralelos apuntados revelan fondos planos o convexos. Lamentablemente, todos los ejemplares registrados se hallaron fuera de contexto, lo que no permite una mayor precisión por asociación de materiales.

En función de la morfología de los bordes se han podido establecer dos subgrupos:

Un primer subgrupo lo constituyen aquellos ejemplares que presentan un cierto engrosamiento del borde 
que, interna o externamente, diferencia al propio borde del cuerpo. Son unas formas muy abiertas y con una escasa profundidad que podrían emparentarse con los platos, por lo que se trata de un recipiente destinado al consumo de alimentos. Si se atiende a la propia configuración del borde podrían realizarse algunas precisiones, como se apunta a continuación a partir de la comparación con los datos estratificados. En general, la mayor parte de las formas documentadas remiten a la cerámica a mano de la Baja Andalucía tartésica de época orientalizante, reproduciéndose muchas de ellas en la tecnología a torno. Es el caso de un cuenco (fig. 4.2: CV/15/368/4) cuyo paralelo exacto se encuentra en la Fase III del Cabezo de San Pedro (Blázquez et al. 1979: fig. 58: 611) y entre las formas a mano del Suroeste del 750-650 a.C. (Pellicer 1987-88: fig. 5:6, 466). Una cronología centrada en el siglo VII presentaría aquel ejemplar (fig. 4.3: CV/26/178/3) cuyos modelos se han hallado en el Cerro Macareno (Ruíz Mata 1995: 273, fig. 19: A:21), Valencina de la Concepción (Ruíz Mata 1995 fig. 19. B:9), Cástulo (Blázquez y Valiente 1981: figs. 95:829, 109:972, 119:1050) o La Bienvenida (Fernández Ochoa et al. 1994: fig. 117:48). Otros especímenes (fig. 4.4: CV/32/2/40) se fecharían en el siglo VI a.C. si se atiende a la posición que ocupan en Medellín (Almagro Gorbea 1977: 130, 449, fig. 48 MT-1), aunque parece que este tipo de cuenco tuvo un origen anterior como constatan los paralelos de Vega de Santa Lucía (Murillo 1994: fig. 4.45: 752) u Osuna (Ferrer et al. 2017: fig. 7:5). Lo mismo ocurre con todas aquellas formas (fig. 4.5: CV/30/96/5, fig. 4.6: CV/33/126/1) semejantes a las de Cástulo (Blázquez y Valiente 1981: figs. 80: 706; 124: 1094) o La Saetilla (Murillo 1994: fig. 4.70: 1688).

Un segundo subgrupo queda representado exclusivamente por un borde más vertical que los anteriores, aspecto que debió otorgarle una mayor profundidad (fig. 4.7: CV/29/188/7). Esta forma aparece en Cástulo (Blázquez y Valiente 1981: fig. 50:412), aunque con una cronología anterior se estratifica en Vega de Santa Lucía (Murillo 1994: fig. 4.46: 742), Peñalosa (García Sanz y Fernández Jurado 2000: lám. 31: 5), Osuna (Ferrer et al. 2017: fig. 17: 9) o Medellín (Jiménez y Guerra 2012: figs. 8: 9; 10: 4).

Este tipo de cuencos se constatan en la Meseta Sur desde el Bronce Final, como en Casa de Rana (Zarzalejos et al. 2012: fig. 15) o Cerro del Gato (Pérez Avilés 1985: fig. 10), aunque estas adscripciones se han establecido a partir de materiales hallados en superficie. Sin embargo, este contexto fue el que se consideró para los cuencos análogos de Extremadura (Vilaça et al. 2012: fig. 5:11), algunos avalados por dataciones radiocarbónicas (Jiménez Ávila y Guerra 2012: 65-110). Pese a ello, las estratigrafías más cercanas lo sitúan en momentos del Hierro I, como Alarcos (Fernández Rodríguez 2012: 51, fig. 8:2) o el Cerro de las Cabezas (Esteban et al. 2003: fig. 7:2), criterio que se ha considerado a la hora de incluir los recipientes de Calatrava la Vieja en esta fase. No obstante, habría que considerar las altas cronologías de los ejemplares extremeños o del Valle del Guadalquivir.

El cuenco de perfil semiesférico con el borde vuelto presenta una amplitud cronológica, geográfica y cultural que dificulta una mayor precisión. Sin embargo, la particularidad en la morfología de los bordes permite una aproximación a tales aspectos. De este modo, las similitudes que se han apuntado abogan por su contextualización en este periodo, en el que se registran una serie de transformaciones socioculturales como consecuencia de los contactos con el Suroeste. Los testimonios materiales que ha proporcionado Calatrava la Vieja corroboran unos contactos entre la Meseta Suroriental y el Suroeste desde el Bronce Final, relaciones que se mantuvieron en la etapa transicional Bronce Final-Hierro I (Miguel 2017: 42-43). De hecho, Alarcos, uno de los yacimientos más cercanos a Calatrava, desarrolló estos contactos en tan alta cronología (García Huerta y Morales 2017: 122-123). Por tanto, la presencia de esta forma en Calatrava podría explicarse como consecuencia de los conexiones con el ámbito tartésico que se venían dando desde el Bronce Final.

2.3.3. Vasos a mano de pareces finas y cuello cilíndrico

En Calatrava la Vieja se ha recuperado un pequeño fragmento sin contexto conocido, con las paredes muy bruñidas y con una gran calidad técnica (fig. 4.8: $\mathrm{CV} / 26 / 12 / 3$ ), tratándose de un recipiente cerrado de reducidas dimensiones, probablemente para contener líquidos. El fragmento parece revelar el típico vaso globular de cuello cilíndrico, aunque se encuentra muy fragmentado y solo permite una reconstrucción parcial. Por tanto, su forma solo podría rastrearse a partir del borde, el cual se ha documentado en recipientes decorados con motivos grafitados o bícromos (rojo y blanco), todos ellos relacionados con el mundo de Campos de Urnas del Valle del Ebro (Werner 1990: figs. 32, 33 y 34: A, B, C). Concretamente, se emparenta con los vasos del Poblado II b de Cortes de Navarra (Maluquer de Motes 1954: figs. 2: 6,9; 4), una fase que se ha fechado entre el 650-550 a.C. (Werner 1990: nota 77). 


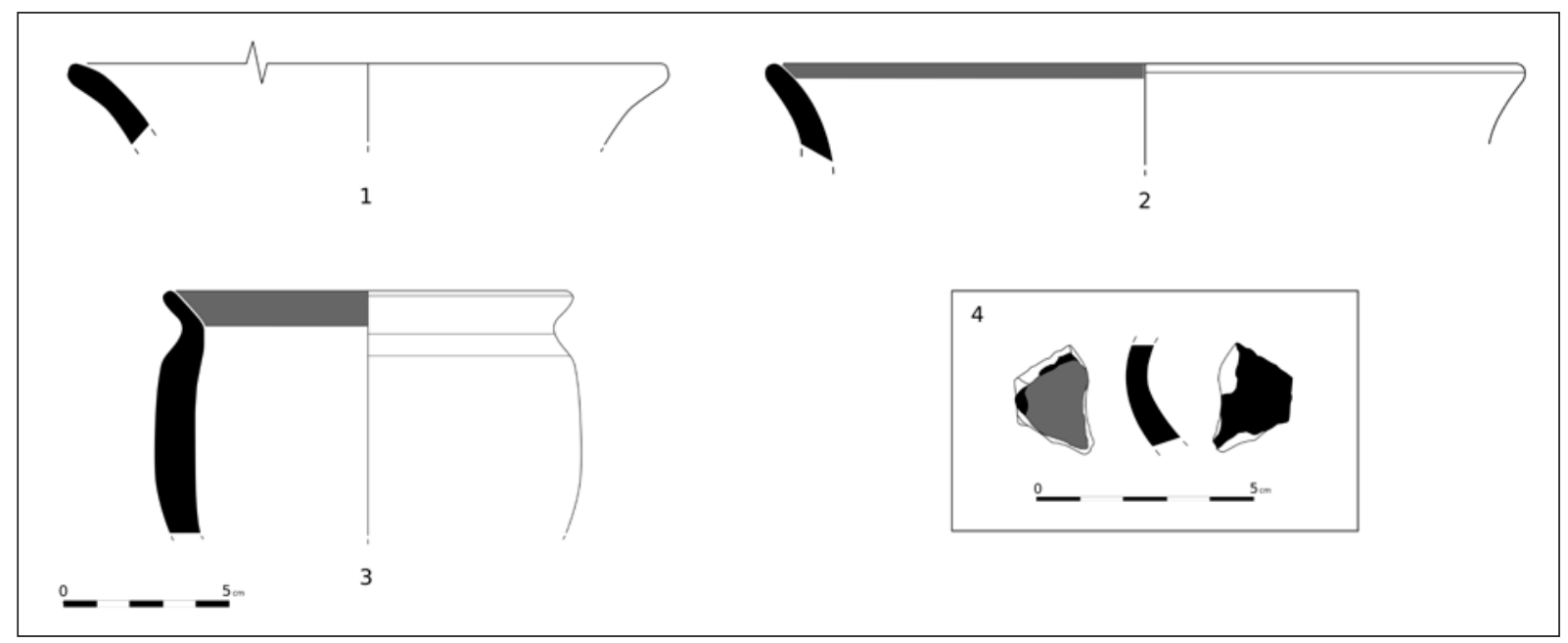

Figura 5. Cerámicas grafitadas de uso restringido (Fuentes: 1 y 2. Vaso globular a mano de borde plano-exvasado y cuello estrangulado: 3. Galbo: 4).

Datos más recientes remiten de nuevo a contextos del Valle Medio del Ebro durante la Primera Edad del Hierro, como los ejemplares de las fases II y III del Cabezo de la Cruz que se fecharon por $\mathrm{C}^{14}$ entre los siglos VIIVI a.C. (Picazo et al. 2004: 380, fig. 17).

En los yacimientos más cercanos no se ha encontrado ningún paralelo que permita una mayor precisión cronológica, por lo que provisionalmente se considera un recipiente de la Primera Edad del Hierro en función de los paralelos apuntados. En cuanto a su vinculación cultural, parece clara su relación con el Valle del Ebro ya que fue típico de esta zona durante este momento. $\mathrm{Su}$ presencia en Calatrava la Vieja testimonia la continuidad de los contactos con la Meseta Norte en tales contextos, unas relaciones que comenzaron en las fases previas como así refleja la cerámica con decoración acanalada o de tradición de Cogotas I.

\subsubsection{Plato a torno con el borde engrosado al exterior}

En la UE 77 del A-16, adscrita al Ibérico Antiguo, se ha constatado un plato de $22 \mathrm{~cm}$ de diámetro y con el borde engrosado al exterior que sería utilizado para el consumo de alimentos o como tapadera (fig. 4.9: $\mathrm{CV} / 16 / 77 / 13)$. Así parece corroborarlo su poca profundidad o el escaso grosor de sus paredes. Además, la pasta está muy depurada y las superficies muy cuidadas. Probablemente deba incluirse entre la cerámica gris ibérica a torno, constatada en esta fase a partir de algunos galbos o un borde con el borde vuelto (fig. 4.10).

\subsection{Cerámica de uso restringido}

\subsubsection{Fuentes a mano}

Entre los materiales fuera de contexto destacan dos bordes a mano muy abiertos que parecen revelar recipientes de gran diámetro $(34 \mathrm{~cm})$ y poca profundidad (fig. 5.1: CV/26/229/101; fig. 5.2: CV/01/25/25/90), probablemente fuentes con perfil en $\mathrm{S}$. Su consideración como formas de uso restringido, ya sea en rituales o banquetes, radica en la aplicación de grafito sobre ambas superficies previamente alisadas o bruñidas. Como algunos autores han apuntado (García Huerta, e. p.), es poco probable el uso habitual de las cerámicas pintadas postcocción ante el deterioro de una pintura poco fija en las superficies. Su inclusión entre formas de la Primera Edad del Hierro se fundamenta en la cronología que se le ha concedido a este horizonte decorativo, aunque en Calatrava la Vieja se han documentado tres fragmentos con decoración grafitada asociados a cerámica a torno ibérica (fig. 5.4: CV/16/77/23).

En cuanto a su morfología, se han documentado bordes similares en Cástulo, generalmente con las superficies bruñidas o alisadas y con diámetros que oscilan entre los 12-40 cm (Blázquez y Valiente 1981: figs. 70: 600; 69: 567; 80: 702, 689; 98: 860; 147: 1258), aunque el ejemplar jienense con el que comparte mayores semejanzas es precisamente aquel que recibió grafito en la superficie externa (Blázquez y Valiente 1981 fig. 72: 614). Las cerámicas grafitadas de Cástulo fueron fechadas a finales del siglo VII-principios del VI 
a.C. (Blázquez y Valiente 1980: 407), una cronología que ha sido aceptada por varios investigadores (Werner 1987-88: 192; 1990: 98; Barroso 2002: 138). De esta forma, los paralelos morfológicos también permiten situar los ejemplares grafitados de Calatrava la Vieja en este periodo.

\subsection{2.. Vaso globular a mano de borde plano- exvasado y cuello estrangulado}

Esta forma, de borde plano-exvasado y cuello estrangulado, comparte muchas características con el tipo G.I de Ruíz Mata (1995: fig. 14: 4). Solo se ha constatado un fragmento de $18 \mathrm{~cm}$ de diámetro (fig. 5.3: $\mathrm{CV} / 15 / 352 / 26)$, lo que revelaría un recipiente de pequeño tamaño para el uso individual. La parte interna del borde fue aplanada, posiblemente para el reposo de algún tipo de tapadera. Como las fuentes anteriores, este vaso se considera de uso restringido por su tratamiento al grafito. Sin embargo, es probable que los recipientes grafitados no fueran utilizados para el consumo de alimentos o bebidas, pues la ingesta del grafito supondría la intoxicación del comensal. Por tanto, es posible que tuviera fines decorativos o como recipiente para contener objetos de adorno personal.

El mejor y más cercano paralelo para este tipo lo encontramos en el estrato $12 \mathrm{~b}$ de Sisapo, aunque con decoración digitada a lo largo del hombro (Fernández Ochoa et al. 1994: fig. 116: 42), o en el Cerro de las Cabezas (Esteban et al. 2003: fig. 4: 4 y 5). Ambos ejemplos se incluyen como formas locales del Hierro I, posición cronológica que compartiría nuestro ejemplar que además presenta el patrón decorativo típico del siglo VI a.C. (Werner 1987-88: 191-192; 1990: 98).

\section{ESTUDIO DEL MATERIAL: LAS DECORACIONES}

\subsection{Cerámica con decoración mamilar}

La decoración a base de mamelones supone un recurso decorativo con una amplia dispersión cronocultural. En Calatrava la Vieja, en función de las formas descontextualizadas a las que aparece asociada, se apuntó un desarrollo durante la fase Bronce Final-Hierro I (Miguel 2017: 42). Los hallazgos de algunos fragmentos decorados con mamelones en la U.E. 80 permiten señalar una continuidad hasta una fase de transición entre la Primera Edad del Hierro y el Ibérico Antiguo (fig. 6.1:
CV/16/80/15). Las formas no se han podido reconstruir, aunque se trataría de vasos cerrados de superficies alisadas y pastas poco decantadas con abundante mica dorada.

\subsection{Cerámica grafitada}

Se trata de uno de los fósiles-guía más representativos del Hierro I en la Meseta (Blasco 1992: 288-290). En Calatrava la Vieja solo han podido recuperarse seis fragmentos, aunque los únicos que han permitido reconstruir sus formas fueron hallados fuera de contexto. Dichas formas corresponden a un recipiente globular (fig. 5.3) y a dos vasos abiertos, probablemente fuentes de perfil en S (figs. 5.1, 5.2). Los tres fragmentos restantes aparecen en el Área 16, todos asociados a cerámica a torno pintada ibérica (fig. 5.4).

Las cerámicas grafitadas de Calatrava la Vieja no permiten apuntar un patrón común en la factura, ya que se documentan pastas marrones, negras o grisáceas como consecuencia de una cocción oxidante, reductora e irregular respectivamente. Todas las superficies son negras o grises, salvo un fragmento con la superficie externa anaranjada. En cuanto al tratamiento de estas, tres son los comportamientos registrados: ambas superficies bruñidas, superficie externa bruñida e interna alisada y, finalmente, ambas superficies alisadas. La elección de un tratamiento u otro dependería del deseo de una mayor o menor adherencia del grafito. De esta forma, si bien las superficies bruñidas ofrecieron un resultado más sobresaliente, las superficies alisadas fueron más idóneas para la fijación del grafito. Parece que la decoración grafitada se aplicó tanto en recipientes cerrados como abiertos, así como en recipientes de gran grosor y en otros de paredes finas ( 5 y $6 \mathrm{~mm}$ ). Sería muy difícil concretar la forma en la que el grafito fue aplicado sobre las superficies del recipiente, aunque el ribeteado que presentan dos de los fragmentos en la superficie interna (figs. 5.2, 2.3) permite apuntar la posible disolución del grafito en una base líquida aplicada con pincel. Lo que sí parece seguro es su aplicación postcocción, ya que, como han demostrado los análisis de las cerámicas grafitadas de Alarcos (García Huerta y Morales 2017: 117), el punto de cocción del vaso haría desaparecer el grafito.

En función de la distribución del grafito, Barroso (2002: 134-136) distinguió varios tipos que no responden a una gradación cronológica, sino al mayor o menor arraigo de algunos tipos en determinadas zonas. Cuatro fragmentos de Calatrava pertenecen al tipo 1, definido 


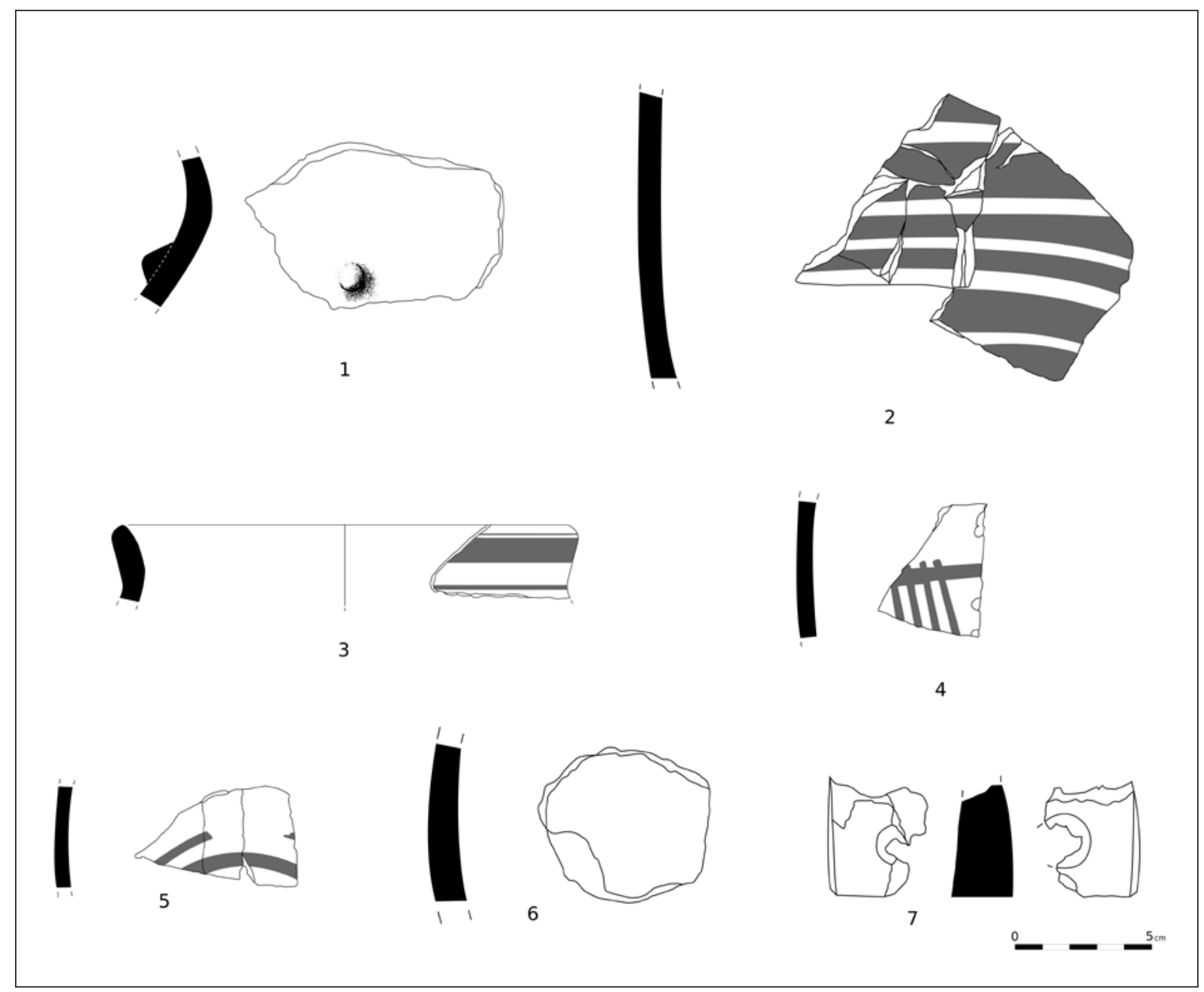

Figura 6. Cerámica con decoración mamilar: 1 y pintada ibérica: 2-5. Ficha de cerámica: 6. Pesa de telar: 7.

por la aplicación de una capa homogénea de grafito en una o ambas superficies (figs. 5.1, 5.4). Dos de los ejemplares estarían entre el tipo 1 y el 2 (figs. 5.2, 5.3), ya que el borde quedó delimitado en la superficie interna por una banda de grafito, mientras que la superficie externa fue cubierta en su totalidad. Ambos tipos presentan una amplia difusión en la Península, concentrándose sobre todo en la Meseta y la mitad sur peninsular.

Werner (1897-88: 191-192; 1990: 97-98) propuso para el grupo de cerámicas con una o ambas superficies homogéneamente grafitadas una cronología que abarca desde finales del siglo VII hasta finales del VI a.C., aunque su floruit se sitúa en la segunda mitad del siglo VI a.C. Esta franja cronológica coincide con las propuestas para las cerámicas grafitadas de Peñarroya, insertas en un momento de transición entre la Primera y la Segunda Edad del Hierro (García Huerta et al. 1999: 237,
218) o de pleno Hierro I (Benítez de Lugo et al. 2004: 66-67). Las cerámicas grafitadas de Alarcos (Fernández Rodríguez 2012: 46, 55-56; García Huerta y Morales 2017: 117) y del Cerro de las Cabezas (Esteban et al. 2003: 19-20, 26) también se han incluido en estos contextos, todas ellas siguiendo los patrones decorativos del tipo 1. De hecho, la última campaña de Alarcos, que ha registrado niveles fechados por $\mathrm{C}^{14}$ en la primera mitad del siglo VIII cal. a.C. según una muestra de vida corta (hueso animal), no ha constatado cerámica grafitada (García Huerta e. p.). Todos estos datos sitúan el inicio de la decoración grafitada en Calatrava la Vieja durante la Primera Edad del Hierro, perdurando hasta los primeros momentos de la iberización.

En cuanto a su filiación cultural, este tipo de cerámica se ha vinculado tradicionalmente a la penetración de los influjos de Campos de Urnas en la península 
ibérica (Blázquez y Valiente 1980: 404-407), diferenciándose dos momentos en función de los horizontes decorativos constatados (Werner 1987-88:185-194; 1990: 97-98). Sin embargo, las nuevas interpretaciones abogan por la asimilación y desarrollo de esta técnica por parte de las poblaciones locales, de ahí la personalidad propia de estas producciones tardías con respecto a los ejemplares del valle del Ebro que sí que pudieron tomar algunas referencias de las producciones ultrapirenaicas (Barroso 2002: 138-140). Es muy posible, no obstante, que las cerámicas grafitadas de Calatrava la Vieja no fueran producciones locales ya que los ejemplares son muy escasos $\mathrm{y}$, además, uno de los testimonios ha hallado paralelos con un fragmento con decoración grafitada de Cástulo.

\subsection{Cerámica a torno pintada ibérica}

La cerámica a torno pintada ibérica aparece estratificada en las UU. EE. 77 y 78 del A-16, permitiendo perfilar una etapa que se ha considerado del Ibérico Antiguo. La mayor parte consiste en fragmentos de cocción oxidante o irregular, con pastas grisáceas o anaranjadas y superficies naranjas o beiges por la aplicación de un engobe. En ocasiones, las superficies externas fueron espatuladas para concederles un aspecto brillante. Todos los fragmentos presentan una decoración pintada previa a la cocción, con motivos en tonos naranjas o rojo vinoso. Los motivos registrados se reducen a simples líneas horizontales (fig. 6.3: CV/16/77/3), bandas de líneas horizontales (fig. 6.2: CV/16/77/11), bandas de líneas oblicuas que parten de una línea horizontal (fig. 6.4: CV/16/78/2) y círculos o semicírculos concéntricos (fig. 6.5: CV/16/78/1+6+10).

Tan solo se ha conservado un borde que se engrosa a partir del cuello, constatando una forma cerrada de 16 cm (fig. 6.3). La decoración, en tono rojo vinoso, se localiza en espacios que marcan las partes que componen la pieza, como la banda y la línea del borde o la línea del cuello. Posiblemente se trate de una olla del subtipo 1.1 (Parreño y Bonet 1992: fig. 26: 3) o una tinajilla del subtipo 2.2.1 (Parreño y Bonet 1992: fig. 5: 5). El resto de los fragmentos no ha permitido conocer las formas, aunque algunos parecen revelar formas abiertas al conservar restos de pintura en la superficie interna.

\section{OTROS MATERIALES}

Los dos únicos restos materiales que no corresponden a recipientes se han documentado en la fase del Ibérico
Antiguo del A-16, reduciéndose tan solo a una ficha cerámica y una posible pesa de telar. La ficha, registrada en la U.E. 78, está realizada a partir de la reutilización de una cerámica a mano de pasta grosera y cocción deficiente (fig. 6.6: CV/16/77/6). La pesa de telar está realizada sobre material pétreo muy poroso (fig. 6.7: $\mathrm{CV} / 16 / 77 / 21)$. Su estado fragmentario dificulta asegurar su verdadera función. En cada uno de los lados se observa una perforación de perfil cónico que al unirse genera una sección de diávolo.

\section{CONSIDERACIONES FINALES: CALATRAVA LA VIEJA DURANTE LA PRIMERA EDAD DEL HIERRO ( $C$. FIN S. VIII a.C-550 a.C.)}

Pese a la dificultad existente en la definición de aquellas fases que abarcan desde finales del Bronce Medio hasta época íbera (Fernández Rodríguez 2012: 42-43; Zarzalejos et al. 2012: 16), se ha podido diferenciar en la Meseta suroriental un periodo del Bronce Final, otro transicional Bronce Final-Hierro I y, finalmente, un Hierro I que enlazaría con el Ibérico Antiguo (Benítez de Lugo et al. 2004: 36-70). En Calatrava la Vieja se han identificado estas tres fases culturales a partir de materiales fuera de contexto (Blanco et al. 2012: 100-106), pudiendo adscribir algunas formas cerámicas en función de los paralelos con otros yacimientos en los que dichas formas aparecen estratificadas (Miguel 2017: 33-45).

Aunque algunos de los yacimientos han proporcionado materiales en superficie que revelarían la existencia de una fase del Bronce Final, como Alarcos (García Huerta y Fernández Rodríguez 2000: figs. 4; 5: 2) o Calatrava la Vieja (Blanco et al. 2012: fig. 4), no es hasta el periodo transicional Bronce Final-Hierro I cuando se constatan niveles arqueológicos que en determinados casos marcarían el momento fundacional del enclave, como La Bienvenida (Fernández Ochoa et al. 1994: 143-145) o el Cerro de las Cabezas (Vélez y Pérez 1987: 167-196; 1999: 51-53). Esta fase transicional se caracterizó en Calatrava la Vieja, como en los yacimientos citados, por sus contactos con otras áreas de la península ibérica, como el Suroeste o la Meseta Norte.

La Primera Edad del Hierro supondría la cristalización de las relaciones entre la Meseta Sur y la Baja Andalucía tartésica, que durante este momento estaba experimentando una fase de pujanza económica y cultural, además de un progresivo aumento de las relaciones con el Sureste como advierten los paralelos con Cástulo. Como consecuencia de estos contactos, y por 
la propia evolución de las poblaciones locales, se registran en el Alto Guadiana unas trasformaciones sociales y culturales que, en muchos casos, se van a caracterizar por una impronta orientalizante. Tanto es así que se ha perfilado para este ámbito un Periodo Orientalizante (Zarzalejos y López Precioso 2005: 809-842, Zarzalejos y Fernández Ochoa 2008: 16), consideración que se ha reafirmado recientemente y que contempla la necesidad de incorporar los territorios más meridionales de la actual provincia de Ciudad Real en el escenario cultural de Tarteso (Zarzalejos et al. 2017: 42).

En términos cronológicos y culturales, el corte A-1 (ab) de La Bienvenida ha ofrecido desde los años noventa la información más segura para secuenciar las fases adscritas entre el Bronce Medio y el Ibérico Antiguo meseta suroriental (Zarzalejos y Fernández Ochoa 2008: 17), por lo que sus materiales estratificados siempre han servido de referencia para ubicar los de otros poblados coetáneos en este espacio geográfico. En dicho corte se identificó un Periodo Orientalizante o Primera Edad del Hierro (estratos 11 y 12) que se fechó entre el 650-550 a.C., dejando entrever un hiatus de 50 o 40 años entre esta fase y la anterior del Bronce FinalHierro I (Zarzalejos et al. 1994: 174). Posteriormente se fechó el Periodo Orientalizante en el Alto Guadiana entre principios del siglo VII y el 550 a.C. (Zarzalejos y Fernández Ochoa 2008: nota 2). Las fechas de $\mathrm{C}^{14}$ del estrato 3 del C-23 de Alarcos corroboran esta consideración cronológica, ya que el siglo VII a.C. quedaría totalmente integrado en esta fase cultural (Fernández Rodríguez 2012: 60-62). Sin embargo, los nuevos hallazgos de La Bienvenida permiten retrotraer los inicios del Periodo Orientalizante a finales del siglo VIII (Zarzalejos et al. 2017: 39-67). Sería a partir de este momento, o quizás antes, cuando se desarrollaron todas aquellas transformaciones socioculturales que definen la Primera Edad del Hierro o Periodo Orientalizante, unas transformaciones del sustrato local que surgen como fruto de los contactos con las poblaciones coloniales y tartésicas. La huella arqueológica de todos estos cambios no solo queda reflejada en las primeras cerámicas a torno o la erección de una arquitectura de filiación tartésica (Zarzalejos et al. 2017: 39-67), sino en el desarrollo del ritual incinerador en el que se emplearon cerámicas estilo Medellín como urna cineraria (Fernández Rodríguez 2012: fig. 13: 2). Teniendo en cuenta la importancia de la dinámica local en el proceso de reinterpretación de todos estos elementos orientalizantes, es evidente el desarrollo de una ideología y modos de vida con paralelos en el Suroeste, donde, desde finales del siglo X cal a.C. (González de Canales et al.
2010: 648; 2017: 47), existían relaciones culturales y comerciales con los fenicios. Este proceso de interacción, no obstante, sería más intenso a partir de la colonización fenicia a partir de 825 cal a.C. (Torres, 2008: 140).

Sabemos que las relaciones entre Alarcos y el Suroeste se remontan al siglo IX cal. a.C. (García Huerta y Morales 2017: 122-123), por lo que sería inviable seguir manteniendo una cronología de mediados del VII a.C. para marcar el inicio del Periodo Orientalizante en el Alto Guadiana, máxime si se está evidenciando que las transformaciones sociales que definen este momento ya son perceptibles a finales del siglo VIII a.C. Por tanto, y dadas las evidencias apuntadas, sería conveniente retrotraer la cronología de la Primera Edad del Hierro o Periodo Orientalizante en el Alto Guadiana, como mínimo y en función de la información disponible, a finales del siglo VIII a.C.

La propuesta planteada solapa el Periodo Orientalizante con la fase transicional Bronce Final-Hierro I del estrato 13 de La Bienvenida, ya que fue fechado a finales del siglo VIII a.C. (Zarzalejos et al. 1994: 173, 2017: 44). Dicha cronología fue establecida, en gran parte, a partir de las copas B.II pintadas al estilo San Pedro II (Zarzalejos et al. 2012: 28-30). Sin embargo, hubo autores que ya apuntaron la posibilidad de situar el desarrollo de este horizonte decorativo en la segunda mitad del VIII a.C. (Torres 2002: 158). De hecho, se ha documentado una copa pintada al estilo San Pedro II en la fase V de El Carambolo (Casado 2015: fig. 51: DJ2002/24/2544-104+110), fase que abarcaría todo el siglo VIII a.C. (Fernández Flores y Rodríguez Azogue 2007: 109). Por otro lado, la Fase II del cabezo de San Pedro se ha situado a mediados del siglo VIII a.C. en función de los nuevos hallazgos en Huelva en fechas convencionales (González de Canales et al. 2017). Además, existen elementos del estrato 13 de La Bienvenida que abogan por una mayor antigüedad, como la cazuela A.I.a decorada con palmas bruñidas (Zarzalejos et al. 2012: fig. 10: 2), inserta en la Fase I de Ruíz Mata (1995: fig. 2, 2014: 5), o el vaso a chardón (Torres 2002: 148-149; Brandherm y Krueger 2017: fig. 6). A ello habría que añadir los paralelos entre los materiales de La Bienvenida y los de Alarcos, como el vaso a chardón con decoración incisa (García Huerta y Morales 2017: fig. 6) o las copas B.II.b.1 y B.II.b.2 pintadas postcocción en rojo (García Huerta y Morales 2017: fig. 8: 2, 8, 11). Estos materiales se fechan entre los siglos IX y Cal a.C. (García Huerta y Morales 2017: tab. 1), lo que permite plantear una mayor antigüedad para el estrato 13 de La Bienvenida según las 
fechas calibradas del cercano yacimiento de Alarcos. Las cerámicas monocromas al estilo san Pedro II pervivirían en La Bienvenida durante el Periodo Orientalizante, como constatan los estratos 12 y 11 del corte A-1 (ab) (Fernández Ochoa et al. 1994: gráficos 3 y 4), el edificio orientalizante del Área 4 (Zarzalejos et al. 2017: fig. 13) y como es habitual en otros enclaves tartésicos del siglo VII a.C. (Torres 2002: 158-160). De este modo, y en función de los datos apuntados, es posible situar el periodo transicional Bronce Final-Hierro I, como mínimo, a mediados del siglo VIII a.C. en el Alto Guadiana. Estas consideraciones cronológicas matizarían el límite inferior que se propuso para esta fase en Calatrava la Vieja (Miguel 2017: 35).

Como ya se indicó, una de las novedades que definen esta etapa, y como consecuencia de los contactos con el Suroeste, fue la irrupción de la cerámica a torno, cuyos porcentajes se incrementaron progresivamente con respecto a la cerámica a mano. Esta circunstancia posiblemente explique la reducción de las formas a mano con respecto a la etapa anterior en Calatrava la Vieja. Muchas de las formas a mano se reprodujeron a torno, como algunos cuencos con el borde vuelto, lo que revela una interacción entre ambas producciones. Aunque no se ha abordado en este trabajo, existen cerámicas grises a torno, polícromas y de barniz rojo que se adscriben a este periodo, lo que indica, junto con las producciones a mano estudiadas, que Calatrava la Vieja no se mostró ajena a la realidad que se estaba desarrollando en el Alto Guadiana durante esta fase cultural. De hecho, se constata la continuidad de las relaciones con el área nuclear tartésica a través de formas tan típicas como la copa B.II.a.1 o los cuencos semiesféricos de borde vuelto. También continuaron las interacciones con el Sureste que, de forma muy débil, se atisbaban en la fase anterior, especialmente con Cástulo. Así, para el caso de las cerámicas grafitadas, se constatan algunos paralelos que podrían corroborar las conexiones con el enclave jienense. Esta red de contactos fue extensible también a entornos más septentrionales, como la Meseta Norte, donde se han encontrado los paralelos para el ejemplar de cuello cilíndrico.

Las relaciones entre el Suroeste y La Mancha debieron articularse a través de la posterior Vía de la Plata (Zarzalejos et al. 2015: 47), ruta que en un principio se valoró para los hallazgos orientalizantes de la tumba principesca de El Carpio (Pereira y de Álvaro 1988: 279-289). Sin embargo, también habría que tener en cuenta la ruta que unió Córdoba con Mérida, atravesando toda Sierra Morena (Torres 2002: 54). Todas las vías terrestres apuntadas son de época romana, aunque es posible que estas siguieran un trazado previo. Entre ellas destaca la que unió Cástulo con Toledo y Complutum, vía que atravesaba toda la Mancha por Mariana, Laminii, Murum y Consaburum (Consuegra) (Torres 2002: 54-55). Este sería el medio por el que debieron forjarse las relaciones entre Cástulo y Calatrava la Vieja, añadiendo además las conexiones entre los distintos poblados coetáneos del Alto Guadiana.

En la actualidad, y a partir de los procesos de interacción entre las poblaciones locales y fenicias en las costas portuguesas desde finales del siglo IX a.C. (Vilaça y Cardoso 2017: 249), se ha valorado la penetración de elementos orientales en un eje oeste-este. Así, para el valle medio del Guadiana se prefiere apuntar esta vía en lugar del tradicional eje sur-norte que después quedó definido por la Vía de la Plata (Rodríguez y Celestino 2017: 216-217). Por lo tanto, es posible que las novedades ideológicas y tecnológicas de raíz oriental llegaran a Calatrava la Vieja a través de este foco, aunque los contactos con la Baja Andalucía, de donde también se recibirían influjos orientales, debieron jalonarse por vía terrestre.

La primera Edad del Hierro supuso una etapa crucial en la configuración de los oppida ibéricos, nacidos al calor del aumento demográfico que durante este momento se registra en este espacio como consecuencia de una apertura comercial. Al igual que ocurrió con el resto de los poblados íberos de la Oretania septentrional (Benítez de Lugo et al. 2004: 69), posiblemente debamos situar aquí el momento clave en la gestación del oppidum que coronó la pequeña elevación de Calatrava la Vieja. No obstante, este importante desarrollo no habría sido posible sin un antecedente fundamental que debe situarse en la etapa transicional Bronce Final-Hierro I.

El final de la Edad del Hierro no supuso una ruptura con el poblamiento de Calatrava la Vieja, ya que mostró continuidad durante el Ibérico Antiguo. Esta continuidad es perceptible en la estratigrafía del A-16, ya que las unidades estratigráficas de la fase correspondiente al Ibérico Antiguo (UU. EE. 77 y 78) reposan directamente sobre aquellas consideradas de finales de la Primera Edad del Hierro o en transición hacia el Ibérico Antiguo (UU. EE. 79, 80 y 81). La fase ibérica ha podido ser definida gracias a la presencia de cerámica a torno pintada con los típicos motivos en rojo vinoso $\mathrm{o}$ anaranjados. Este dato, unido a la presencia de cerámica grafitada, fecharía esta fase en el siglo VI a.C., aunque el inicio de la decoración al grafito se remontaría a época anterior. De esta forma, las unidades sobre las que reposa esta fase serían inmediatamente anteriores, con cerámica a torno muy fragmentada y de pastas 
oxidantes. Esta cerámica a torno convivió con una cerámica a mano que perpetúa formas y decoraciones anteriores, como las ollas o la cerámica grafitada. Aunque la exigüidad de los materiales estratificados en Calatrava la Vieja es evidente, reviste gran interés a la hora de valorar el voluminoso material fuera de contexto que se ha ido exhumando en las sucesivas campañas. De hecho, ha permitido aclarar aspectos sobre algunos de los materiales sin contexto que se han presentado, como la cerámica grafitada. El estudio de la estratigrafía también ha permitido señalar una continuidad de la población de Calatrava la Vieja, por lo que no hubo una ruptura con el inicio de la época íbera.

Esta temprana iberización de las poblaciones del Alto Guadiana tras una fase del Hierro I u Orientalizante, sin hiatus aparente, es perceptible en los poblados aledaños de La Bienvenida (Esteban y Hevia 2008: 85), el cerro de las Cabezas (Vélez y Pérez 2008: 39) o Alarcos (Fernández Rodríguez 2008: 64). Esta realidad sería extensible a otros oppida de la posterior Oretania más oriental, como Mentesa Oretana (Benítez de Lugo, 2004: 269-274). En estos enclaves, al igual que ocurre en Calatrava la Vieja, ya aparecen los elementos típicos de la cultura ibérica desde mediados del siglo VI a.C.

En definitiva, y a partir de la información que ofrecen los materiales estratificados y fuera de contexto, Calatrava la Vieja fue un enclave que desarrolló una red de contactos comerciales y culturales con otras áreas peninsulares durante la Primera Edad del Hierro. Por tanto, experimentó una dinámica similar a la de otros poblados coetáneos de la zona, como Alarcos, La Bienvenida o el Cerro de las Cabezas. Parece ser que también existió una continuidad poblacional durante los primeros momentos de la cultura ibérica, aspecto que también se percibe en las estratigrafías de los yacimientos apuntados. Sin embargo, la información recabada de un material mayoritariamente descontextualizado solo permite un esbozo a la espera de poder hallar niveles de esta época.

\section{Agradecimientos}

Este trabajo ha podido realizarse gracias a la concesión de un contrato predoctoral para la formación de personal investigador del plan propio de la Universidad de Castilla-La Mancha. Quería agradecer públicamente al Dr. Don Manuel Retuerce Velasco (UCM) y al Dr. Don Miguel Angel Hervás, ambos directores del yacimiento de Calatrava la Vieja, la cesión de los materiales estudiados en este trabajo, así como a la Dra. Dña. María del Rosario García Huerta (UCLM) y al Dr. D. Mariano Torres Ortiz (UCM) la revisión del trabajo previo a su publicación. También quería agradecer la ayuda y colaboración de Alejandro Pérez Miguel y Javier Martínez-González.

\section{BIBLIOGRAFÍA}

Almagro Gorbea, M. (1977): El Bronce Final y el Periodo Orientalizante en Extremadura. Madrid. Bibliotheca Praehistorica Hispana 14.

Barroso, R. (2002): “Cuestiones sobre las cerámicas grafitadas del Bronce Final y la I Edad del Hierro de la Península Ibérica". Trabajos de Prehistoria 59 (1): 127-142. Disponible en: http://tp.revistas.csic. es/index.php/tp/article/viewFile/214/214

Benítez de Lugo, L. (2004): “Conclusiones y valoración final 1998-2000”, en L. Benítez de Lugo (dir.), Mentesa Oretana: 269-274. Ciudad Real, Anthopos.

Benítez de Lugo, L.; Esteban, G. y Hevia, P. (2004): Protohistoria y Antigüedad en la provincia de Ciudad Real. Ciudad Real, C\&G.

Blanco, J. F.; Hervás, M. A. y Retuerce, M. (2012): "Una primera aproximación arqueológica al oppidum oretano de Calatrava la Vieja (Carrión de Calatrava, Ciudad Real)", en J. Aparicio y L. Silgo (eds.), Real Acadèmia de Cultura Valenciana. Sección de estudios ibéricos "D. Fletcher Valls". Estudios de lenguas y epigrafía antiguas 12: 85-150. Valencia.

Blasco, M. a C. (1992): "Etnogénesis de la Meseta Sur". Paleoetnología de la Península Ibérica. Complutum 2-3: 281-297. Disponible en: https://revistas.ucm.es/index.php/CMPL/article/view/CMPL9292120281A

Blasco, M. ${ }^{\text {a C}}$; Carrión, E. y Planas, M. (1998): “Datos para la definición de la Edad del Hierro en el ámbito carpetano: El yacimiento de Arroyo Culebro". Cuadernos de Prehistoria y Arqueología de la Universidad Autónoma de Madrid 25 (1): 245-281. Disponible en: https://revistas.uam.es/cupauam/article/view/1273

Blázquez, J. M. a; Ruíz Mata, D.; Remesal J.; Ramírez, J. L. y Clauss, K. (1979): Excavaciones en el Cabezo de San Pedro (Huelva). Campaña de 1977. (Excavaciones arqueológicas en España 102). Madrid, Ministerio de Cultura.

Blázquez, J. M. a y Valiente, J. (1980): “Cerámicas grafitadas del poblado de La Muela de Cástulo (Linares, Jaén)". Trabajos de Prehistoria 37: 399-418. 
Blázquez, J. M. ${ }^{\mathrm{a}}$ y Valiente J. (1981): Cástulo III. (Excavaciones Arqueológicas en España 117). Madrid, Ministerio de Cultura.

Brandherm, D. y Krueger, M., (2017): "Primeras determinaciones radiocarbónicas de la necrópolis de Setefilla (Lora del Río) y el inicio del periodo orientalizante en Andalucía occidental". Trabajos de Prehistoria 74 (2): 296-318. Disponible en: http://tp.revistas.csic.es/index.php/tp/article/ view/758/782

Cabrera, P. (1981): "La cerámica pintada de Huelva". Huelva Arqueológica V: 317-335.

Casado, M. (2015): La cerámica con decoración geométrica del Carambolo. Spal Monografías XXI. Sevilla, Universidad de Sevilla.

Esteban, G.; Hevia, P.; Pérez J. J. y Vélez, J. (2003): "La transición del Bronce Final a la Primera Edad del Hierro en el Cerro de las Cabezas (Valdepeñas, Ciudad Real)". Cuadernos de Estudios Manchegos 25-26: 11-42. Disponible en: http://biblioteca2.uclm.es/biblioteca/ceclm/ARTREVISTAS/ cem/cem 2526 transici\%F3nbronce.pdf

Esteban, G. y Hevia, P. (2008): "El Periodo Ibérico Antiguo en la Bienvenida y su entorno", en J. Jiménez Ávila (coord.), Siderum Ana I. El río Guadiana en época post-orientalizante. Anejos de Archivo Español de Arqueología XLVI: 81-98. Mérida, CSIC.

Fernández Flores, A. y Rodríguez Azogue, A. (2007): Tartessos desvelado. Córdoba, Almuzara.

Fernández Jurado, J. (1988-89): Tartessos y Huelva. (Huelva Arqueológica 10-11).

Fernández Martínez V. M.; Hornero del Castillo, E. y Pérez Muga, J. A. (1994): "El poblado ibérico del "Cerro de las Nieves" (Pedro Muñoz). Excavaciones de 1984-1985”, en J. Sánchez Meseguer, C. Galán, A. Caballero, C. Fernández Ochoa y M. ${ }^{\mathrm{a}}$. T. Musat (coords.), Jornadas de Arqueología en Ciudad Real en la Universidad Autónoma de Madrid: 111-130. Toledo, Servicio de Publicaciones de la Junta de Comunidades de Castilla-La Mancha.

Fernández Ochoa, C.; Zarzalejos, M.; Hevia, P. y Esteban, G. (1994): Sisapo I. Excavaciones arqueológicas en "La Bienvenida”, Almodóvar del Campo (Ciudad Real). Toledo, Servicio de Publicaciones de la Junta de Comunidades de CastillaLa Mancha.

Fernández Rodríguez, M (2008): "El oppidum de Alarcos en los siglos VI-V a.C.”, en J. Jiménez Ávila (coord.), Siderum Ana I. El río Guadiana en época post-orientalizante. Anejos de Archivo Español de Arqueología XLVI: 61-79. Mérida, CSIC.
Fernández Rodríguez, M. ${ }^{a}$ D. M. (2012): “Apuntes sobre el Bronce Final y la Primera Edad del Hierro en Alarcos (Ciudad Real)," en J. Jiménez Ávila (ed.), Siderum Ana II. El río Guadiana en el Bronce Final. Anejos del Archivo Español de Arqueología LXII: 41-64. Mérida, CSIC.

Ferrer, E.; Ruíz Cecilia, J. I. y García Fernández, J. (2017): "Nuevos datos sobre el Bronce Final en Osuna”, en S. Celestino y E. Rodríguez (eds.), Territorios comparados: los valles del Guadalquivir, el Guadiana y el Tajo en época tartésica. Anejos de Archivo Español de Arqueología LXXX: 79-127. Mérida, CSIC.

García Huerta, M. ${ }^{a}$ R.; Morales Hervás, F. J. y Ocaña Carretón, A. (1999): "El poblado de la Edad del Hierro de Peñarroya (Argamasilla de Alba, Ciudad Real)", en I Jornadas de Arqueología ibérica en Castilla-La Mancha: 221-258. Iniesta. Junta de Comunidades de Castilla-La Mancha, Consejería de Educación y Cultura.

García Huerta, M. ${ }^{a}$ R. y Fernández Rodríguez, M. ${ }^{a}$ D. M. (2000): "La génesis del mundo ibérico en la Submeseta Sur: El tránsito del Bronce Final-I Edad del Hierro en Alarcos". Cuadernos de Prehistoria y Arqueología de la Universidad Autónoma de Madrid 26: 47-68. Disponible en: https://revistas.uam. es/cupauam/article/view/1250

García Huerta, M. ${ }^{a}$ R.; Morales, F. J.; Vélez, J.; Soria, L. y Rodríguez, D. (2006): "Hornos de pan en la Oretania septentrional". Trabajos de Prehistoria 63 (1): 157-166. Disponible en: http://tp.revistas.csic. es/index.php/tp/article/view/10/10

García Huerta, M. ${ }^{\text {a }}$ R. y Morales, F. J. (2017): "El poblado de Alarcos (Ciudad Real) en los inicios del I milenio a.C.: estructuras y materiales cerámicos". Trabajos de Prehistoria 74 (1): 108-126. Disponible en: http://tp.revistas.csic.es/index.php/tp/article/view/745/768

García Huerta, M. ${ }^{a}$ R. (e.p): "Las cerámicas pintadas postcocción de la Meseta Sur: el ejemplo de Alarcos (Ciudad Real)", en Las cerámicas a mano pintadas de la Península Ibérica durante la I Edad del hierro (Mérida, 2017), Mérida.

García Pérez, T. (1987): "La motilla de los Romeros. Alcázar de San Juan (Ciudad Real)". Oretum III: 111-165. Disponible en: https://ceclmdigital2.uclm. es/viewer.vm?id=0001803263\&page $=1 \&$ search $=\&$ lang=es\&view $=$ revistas

García Sanz, C. y Fernández Jurado, J. (2000): “Peñalosa (Escacena del Campo, Huelva). Un poblado de cabañas del Bronce Final". Huelva Arqueológica 
16: 5-87. Disponible en: https://dialnet.unirioja.es/ ejemplar/7418

González de Canales, F.; Serrano Picardo, L. y Llompart Gómez, J. (2010): "El inicio de la Edad del Hierro en el Suroeste de la Península Ibérica, las navegaciones precoloniales y cuestiones en torno a las cerámicas locales de Huelva", en J. A. Pérez Macías y E. Romero Bomba (eds.), IV Encuentro de Arqueología del Suroeste Peninsular: 648-697. Aracena (2009). Huelva. Servicio de Publicaciones de la Universidad de Huelva.

González de Canales, F.; Serrano Picardo, L.; Llompart Gómez, J.; García Fernández, M.; Ramón Torres, J.; Domínguez Monedero, A. J. y Montaño Justo, A. (2017): "Archaeological Finds in the Deepest Anthropogenic Stratum at 3 Concepción Street in the City of Huelva (Spain)". Ancient West and East 16: 1-61. Disponible en: http://poj.peeters-leuven. be/content.php?url=article\&id=3214933\&journal_ code $=$ AWE

Jiménez, J. y Guerra, S. (2012): "El Bronce Final en Medellín. Estudio preliminar del corte SMRO”, en J. Jiménez Ávila (ed.), Siderum Ana II. El río Guadiana en el Bronce Final. Anejos de Archivo Español de Arqueología LXII: 65-110. Mérida, CSIC.

Maluquer de Motes, J. (1954): "Los poblados de la Edad del Hierro de Cortes de Navarra". Zephyrus 5: 1-22. Disponible en: http://revistas.usal.es/index. php/0514-7336/article/view/3291/3315

Miguel, P. (2017): "Hacia la configuración del oppidum oretano: Calatrava la Vieja en la transición Bronce Final-Hierro I". Cuadernos de Prehistoria y Arqueología de la Universidad Autónoma de Madrid 43: 33-45. Disponible en: https://revistas.uam.es/ cupauam/article/view/9035

Morales, F. J. (2010): El poblamiento de la época íbera en la Provincia de Ciudad Real. Cuenca, Ediciones de Castilla-La Mancha.

Murillo, J. F. (1994): La cultura tartésica en el Guadalquivir Medio. Ariadna 13-14.

Parreño, C. y Bonet, H. (1992): “La cerámica ibérica: ensayo de tipología", en Estudio de arqueología ibérica y romana. Homenaje a Enrique Pla Ballester: 117-174. Valencia, Servicio de Investigación Prehistórica.

Pellicer, M. (1984): "Elementos ultrapirenaicos y hallstatizantes en el horizonte del Bronce FinalHierro del Noreste hispano". Habis 15: 309-343. Disponible en: https://dialnet.unirioja.es/servlet/ articulo? codigo $=57740$
Pellicer, M. (1987-88): “Las cerámicas a mano del Bronce Reciente y del Orientalizante en Andalucía Occidental". Habis 18-19: 461-483. Disponible en: https://dialnet.unirioja.es/servlet/ articulo? codigo $=57829$

Pereira, J. y De Álvaro, E. (1988): "Una tumba de la transición Bronce-Hierro en la Meseta Sur: El Carpio (Belvis de La Jara, Toledo)", en I Congreso de Historia de Castilla-La Mancha: 279-289, Toledo, Servicio de publicaciones de la Junta de Comunidades de Castilla-La Mancha.

Pérez Avilés, J. J. (1985): “Estudio arqueológico del Campo de Montiel”. Oretum, I: 175-237. Disponible en: https://ceclmdigital2.uclm.es/viewer.vm?id $=0001803261 \&$ page $=1 \&$ search $=\&$ lang $=$ es\&view $=$ revistas

Picazo, J. V.; Pérez, F. y Fatás, L. (2004): “Los materiales. Las cerámicas modeladas a mano", en Los poblados de la Edad del Bronce y de Primera Edad del Hierro del Cabezo de la Cruz (La Muela, Zaragoza): 344-382. Zaragoza, Gobierno de Aragón, Departamento de Educación, Cultura y Deporte.

Retuerce, M. (1994): “Calatrava la Vieja. Diez años de investigación arqueológica”, en J. Sánchez Meseguer, C. Galán, A. Caballero, C. Fernández Ochoa, y M. ${ }^{\mathrm{a}}$ T. Musat (coords.), Jornadas de Arqueología en Ciudad Real en la Universidad Autónoma de Madrid: 212-241. Toledo, Servicio de publicaciones de la Junta de Comunidades de Castilla-La Mancha.

Retuerce, M. y Hervás, M. A. (2004): “Excavaciones arqueológicas en Calatrava La Vieja", en Investigaciones arqueológicas en Castilla-La Mancha 19962002: 381-394. Salamanca, Servicio de Publicaciones de la Junta de Comunidades de Castilla-La Mancha.

Rodríguez Díaz, A. (1990): “Continuidad y ruptura cultural durante la Segunda Edad del Hierro en Extremadura", en La cultura tartésica y Extremadura. (Cuadernos emeritenses 2): 127-162. Mérida, Museo Nacional de Arte Romano.

Rodríguez González, E. y Celestino, S. (2017): “El Valle Medio del Guadiana durante la I Edad del Hierro: una nueva lectura sobre su organización territorial”, en S. Celestino, y E. Rodríguez (eds.), Territorios comparados: los valles del Guadalquivir, el Guadiana y el Tajo en época tartésica. Anejos de Archivo Español de Arqueología LXXX: 213236. Mérida, CSIC.

Ruíz Mata, D. (1995): “Las cerámicas del Bronce Final. Un soporte tipológico para delimitar el espacio y 
el tiempo tartésico", en Tartessos, 25 años después (1968-1993). Actas del Congreso Conmemorativo del V Symposium Internacional de Prehistoria Peninsular: 265-313. Cádiz, 1993, Ayuntamiento de Jerez de la Frontera.

Ruíz Mata, D. (2014): “La cerámica pintada geométrica tartésica", La pieza del mes (27 de septiembre de 2014), Museo Arqueológico Municipal de Jerez/ Asociación de Amigos del Museo: 1-11. Disponible en: http://www.jerez.es/fileadmin/Image_Archive/ Museo/Pieza_sept._La_ceramica_tartesica.pdf

Ruíz Zapatero, G. (2007): “Antes del Hierro. Cultura y sociedad en el centro de la meseta (ca. 1200-500 a.C.)". Zona Arqueológica 10 (1): 36-63.

Torres, M. (2002): Tartessos. Madrid, Bibliotheca Archaeologica Hispana 14.

Torres, M. (2008): "The Chronology of the Late Bronze Age in Western Iberia and the beginning of the Phoenician". A new Dawn for the Dark Age? Scrifting Paradigms in Mediterranean Iron Age Chronology. BAR International Series 1871: 135-147.

Vélez, J. y Pérez, J. J. (1987): “El yacimiento protohistórico del Cerro de las Cabezas (Valdepeñas. Ciudad Real)". Oretum, III: 167-196. Disponible en: https://ceclmdigital2.uclm.es/viewer.vm?id= $0001803263 \&$ page $=1 \&$ search $=\&$ lang $=$ es \& view $=$ revistas

Vélez, J. y Pérez, J. (1999): “Oretanos en la Meseta Sur. El yacimiento ibérico del Cerro de las Cabezas". Revista de Arqueología 213: 46-55.

Vélez, J. y Pérez, J. (2008): “Un espacio de culto del siglo V en el Cerro de las Cabezas (Valdepeñas, Ciudad Real)", en J. Jiménez Ávila (coord.), Siderum Ana I. El río Guadiana en época post-orientalizante. Anejos de Archivo Español de Arqueología XLVI: 37-59. Mérida, CSIC.

Vilaça, R.; Jiménez J. y Galán, E. (2012): “El poblado de los Concejiles (Lobón, Badajoz)”, en J. Jiménez Ávila (ed.), Siderum Ana II. El río Guadiana en el Bronce Final. Anejos de Archivo Español de Arqueología LXII: 125-165. Mérida, CSIC.

Vilaça, R. y Cardoso, J. L. (2017): “O Tejo portugués durante o Bronze Final”, en S. Celestino y E. Rodríguez (eds.), Territorios comparados: los valles del Guadalquivir, el Guadiana y el Tajo en época tartésica. Anejos de Archivo Español de Arqueología LXXX: 237-282. Mérida, CSIC.
Werner, S. (1987-88): “Consideraciones sobre la cerámica con decoración grafitada de la Península Ibérica". Kalathos 7-8: 185-194.

Werner, S. (1990): La cerámica pintada geométrica del Bronce Final y de la Primera Edad del Hierro. Madrid, La Muralla.

Zarzalejos, M.; Fernández Ochoa, C.; Hevia, P. y Esteban, G. (1994): "Excavaciones en La Bienvenida (Ciudad Real). Hacia una definición preliminar del horizonte histórico-arqueológico de la Sisapo antigua”, en J. Sánchez Meseguer, C. Galán, A. Caballero, C. Fernández Ochoa y M. ${ }^{\mathrm{a}}$ T. Musat (coords.), Jornadas de Arqueología en Ciudad Real en la Universidad Autónoma de Madrid: 167-194. Toledo, Servicio de Publicaciones de la Junta de Comunidades de Castilla-La Mancha.

Zarzalejos, M. y López Precioso, F. J. (2005): “Apuntes para una caracterización de los procesos orientalizantes en la Meseta Sur", en S. Celestino y J. Jiménez Ávila (eds.), El Periodo Orientalizante. Anejos de Archivo Español de Arqueología XXXV: 809842. Mérida, CSIC.

Zarzalejos, M. y Fernández Ochoa, C. (2008): "El horizonte Ibérico Antiguo en el Alto Guadiana”, en J. Jiménez Ávila (coord.), Siderum Ana I. El río Guadiana en época post-orientalizante. Anejos de Archivo Español de Arqueología XLVI: 15-36. Mérida, $\mathrm{CSIC}$.

Zarzalejos, M.; Esteban, G. y Hevia, P. (2012): “El Bronce Final en el Alto Guadiana. Viejos y nuevos datos para una lectura histórica", en J. Jiménez Ávila (ed.), Siderum Ana II. El río Guadiana en el Bronce Final. Anejos de Archivo Español de Arqueología LXII: 15-40. Mérida, CSIC.

Zarzalejos, M.; Fernández C.; Esteban, G. y Hevia, P. (2015): "Contribuciones al conocimiento del territorio de Sisapo (La Bienvenida, Almodóvar del Campo) en la Antigüedad: una visión arqueológica", en I Congreso Nacional. Ciudad Real y su provincia: 39-56. Ciudad Real (2015), Ciudad Real, Instituto de Estudios Manchegos.

Zarzalejos, M.; Esteban, G. y Hevia, P. (2017): “El Alto Guadiana entre los siglos VIII y VI a.C. Novedades estratigráficas en el área 4 de Sisapo-La Bienvenida (Almodóvar del Campo-Ciudad Real)", en Jiménez Ávila (ed.), Siderum Ana III. El río Guadiana y Tartessos: 41-67. Mérida. Serie compacta. 